\title{
Ulipristal acetate: a novel pharmacological approach for the treatment of uterine fibroids
}

This article was published in the following Dove Press journal:

Drug Design, Development and Therapy

20 February 2014

Number of times this article has been viewed

\author{
Nicoletta Biglia' \\ Silvestro Carinelli² \\ Antonio Maiorana ${ }^{3}$ \\ Marta D'Alonzo' \\ Giuseppe Lo Monte ${ }^{4}$ \\ Roberto $\mathrm{Marci}^{4}$ \\ 'Department of Obstetrics and \\ Gynaecology, Mauriziano "Umberto I" \\ Hospital, University of Turin, Turin, \\ ${ }^{2}$ Department of Pathology, European \\ Institute of Oncology, Milan, \\ ${ }^{3}$ Department of Obstetrics and \\ Gynecology, ARNAS Civico Hospital, \\ Palermo, ${ }^{4}$ Department of Morphology, \\ Surgery and Experimental Medicine, \\ Section of Obstetrics and Gynecology, \\ Infertility Unit, University of Ferrara, \\ Ferrara, Italy
}

\begin{abstract}
Uterine fibroids are the most common benign tumors of the female genital tract. The management of symptomatic fibroids has traditionally been surgical; however, alternative pharmacological approaches have been proposed to control symptoms. To date, gonadotropinreleasing hormone analogs are the only available drugs for the preoperative treatment of fibroids. However, the US Food and Drug Administration recently authorized ulipristal acetate (UPA), an oral selective progesterone-receptor modulator, for the same indication. UPA is a new, effective, and well-tolerated option for the preoperative treatment of moderate and severe symptoms of uterine fibroids in women of reproductive age. According to clinical data, UPA shows several advantages: it is faster than leuprolide in reducing the fibroid-associated bleeding, it significantly improves hemoglobin and hematocrit levels in anemic patients, and it grants a significant reduction in the size of fibroids, which lasts for at least 6 months after the end of the treatment. Furthermore, UPA displays a better tolerability profile when compared to leuprolide; in fact, it keeps estradiol levels at mid follicular phase range, thereby reducing the incidence of hot flushes and exerting no impact on bone turnover. On the grounds of this evidence, the administration of $5 \mathrm{mg} /$ day ulipristal acetate for 3 months is suggested for different patient categories and allows for planning a treatment strategy tailored to meet an individual patient's needs.
\end{abstract}

Keywords: ulipristal acetate, uterine fibroids, myomas, selective progesterone-receptor modulator, medical treatment of uterine fibroids

\section{Introduction}

Uterine fibroids (or myomas) are monoclonal tumors of the smooth muscle cells of the uterus. They are considered the most common benign tumors of the female genital tract, as they are clinically apparent in up to $25 \%$ of women irrespective of their age. Moreover, they occur in up to $30 \%-40 \%$ of women over the age of $40 .{ }^{1}$ The reported incidence ranges from $30 \%$ to $70 \%$ in premenopausal women and increases with age. ${ }^{2}$ Both the etiology and biology of uterine fibroids are poorly understood, but strong evidence supports the role of hormonal factors (estrogens and progestogens) in favoring tumor growth. ${ }^{3-4}$ Myomas rarely appear before menarche ${ }^{5}$ and frequently regress after menopause. Several risk factors have been identified, such as ethnicity, nulliparity, genetics, and hormonal factors. Symptomatic women typically suffer from abnormal uterine bleeding, which is usually heavy and prolonged and hence results in anemia. Moreover, affected women frequently report dysmenorrhea, dyspareunia, non-cyclic pelvic pain and urinary symptoms (ie, bladder tenesmus). As one can easily infer, uterine fibroids can negatively affect a woman's quality of life and work productivity. In a recent paper, $53.7 \%$ women reported a dramatic decline in their quality of life, due to a
Correspondence: Roberto Marci Department of Morphology, Surgery and Experimental Medicine, Section of Obstetrics and Gynecology, Infertility Unit, University of Ferrara, Corso Giovecca 183, 44I21, Ferrara, Italy Email roberto.marci@unife.it 
general impairment in sexual life (42.9\%), work productivity $(27.7 \%)$, as well as family and daily life $(27.2 \%){ }^{6}$

This review analyses clinical studies on the use of ulipristal acetate (UPA), an oral selective progesterone modulator (SPRM), for the pharmacological management of uterine fibroids. UPA may be a new, effective, and well-tolerated option for the preoperative treatment of moderate and severe symptoms in reproductive age women.

\section{Pharmacological management of uterine fibroids}

The management of symptomatic fibroids has traditionally been surgical; however, alternative pharmacological treatments have been proposed to control symptoms. The choice of the appropriate therapeutic approach depends on several factors, including: age, parity, childbearing aspirations, extent and severity of symptoms, size, number and location of myomas, risk of malignancy, and proximity to menopause.

Oral combined contraceptive pills are often used to control menorrhagia and dysmenorrhea. However, combined pills may cause an increase in the size of myomas. ${ }^{6}$

Besides exerting a direct anti-estrogenic effect at the cellular level, progestational agents may also inhibit gonadotropin secretion and suppress ovarian function, thereby producing an additional hypoestrogenic effect. ${ }^{6}$ Danazol is chemically related to 17 -ethinyl testosterone, which creates a hormonal milieu characterized by high androgen and low estrogen levels. Therefore, it induces endometrial hypotrophy and enhances the shrinkage of the fibroids. However, several side effects have been described, including acne, hirsutism, weight gain, irritability, musculoskeletal pain, hot flushes, and breast atrophy. In addition to that, no randomized controlled trial has proven that the benefits of danazol outweigh its risks, when treating uterine fibroids. ${ }^{7}$ The use of a levonorgestrel intrauterine device (LNG-IUS) has been associated with a reduction in menstrual blood loss in women with uterine myomas, but its effect on the size of uterine myoma is still debated. ${ }^{8}$ LNG-IUS is contraindicated in the case of fibroidassociated severe distortion of the uterine cavity (LNG-IUS SmPC), because of the high expulsion rate..$^{8-10}$

Furthermore, gonadotropin-releasing hormone analogs (GnRHa) proved to be successful both as a conservative treatment and as a preoperative therapy of myomas. They are highly effective in reducing both the symptoms (bleeding, anemia, and abdominal pain) and the volume of fibroids. ${ }^{11,12}$ However, these effects are transient and the myomas usually return to pre-therapy size within a few months of discontinuation. Preoperative GnRHa treatment before myomectomy decreases the size and vascularity of the myoma but may make the capsule more fibrous and hence difficult to resect. Furthermore, some of the treatment-associated adverse effects (menopausal symptoms, osteoporosis, and pelvic pain) could benefit from a hormonal add-back although it may reduce the beneficial effects of GnRHa on myoma size. ${ }^{13}$

Recently, the potential therapeutic role of non-steroidal aromatase inhibitors has been suggested. ${ }^{14}$ Aromatase inhibitors appear as effective as GnRHa, and have fewer side effects. However, the use of these drugs is presently restricted to infertile women due to the unknown influence of body mass index on treatment efficacy, the sparse data on subsequent reproductive outcome, and the absence of longterm follow-up data. ${ }^{15}$

\section{Mechanism of action of ulipristal acetate in the treatment of uterine fibroids}

In uterine fibroids estrogen and progesterone receptors are expressed at higher levels than in normal myometrium. ${ }^{16}$ The influence of estrogen on fibroid growth is well-known, while the role of progesterone and the progesterone-receptor (PR), as well as ovarian steroids has emerged only recently. In fact, biochemical and clinical studies have suggested that the former may enhance proliferative activity in fibroids and the latter may influence fibroid growth. ${ }^{17}$ These observations have inspired studies testing the efficacy of anti-progestins in the medical management of uterine fibroids.

Selective progesterone-receptor modulators (SPRMs) are a new class of PR ligands displaying tissue-selective agonist/ antagonist/mixed activity on target cells. ${ }^{18}$ UPA is an orally active synthetic SPRM, characterized by a tissue-specific partial progesterone antagonist effect. ${ }^{19}$

Progesterone normally promotes fibroid growth in two ways: on the one hand, it up regulates epidermal growth factor (EGF) and Bcl-2 gene, on the other hand it down regulates the tumor necrosis factor gene (TNF). UPA, as a progesterone antagonist, inhibits the proliferation of leiomyoma cells and induces apoptosis by increasing cleaved caspase- 3 expression and decreasing Bcl-2 expression. ${ }^{17}$ Moreover, UPA down regulates the expression of angiogenic growth factors, such as vascular endothelial growth factor (VEGF) and their receptors. Thus, it suppresses neo-vascularization, cell proliferation, and survival in leiomyoma cells but not in normal myometrial cells. ${ }^{20}$ Additionally, UPA increases the expression of matrix metalloproteinases (MMPs) and decreases the expression of tissue inhibitor of metalloproteinases (TIMPs) and collagens in cultured fibroid cells. Thus, UPA may impair 
fibroid tissue integrity by reducing the deposition of collagen in the extracellular spaces. ${ }^{21}$

Besides, UPA acts on the hypothalamic-pituitary-ovarian axis, thereby inhibiting or delaying ovulation and inducing amenorrhea. Since UPA does not alter basal levels of luteinizing hormone and follicle stimulating hormone, estradiol levels remain within the physiological mid-follicular range $(60-150 \mathrm{pg} / \mathrm{mL})$ and hence the symptoms of estrogen deprivation do not occur. However, UPA induces amenorrhea in most women due to its interaction with endometrial progesterone receptors. ${ }^{19,20}$ In conclusion, UPA selectively acts on uterine fibroids and their related symptoms and represents a promising new option for the pre-surgical medical treatment of uterine fibroids.

\section{Therapeutic efficacy of ulipristal acetate}

The administration of 5-10 mg/day UPA for up to 3 months has been proposed as a preoperative treatment for moderate to severe fibroid-associated symptoms. Its clinical efficacy and tolerability profile have been the object of two randomized, double-blind, multinational, Phase III trials (Table 1). PEARL I (PGL4001 versus placebo in uterine myomas) has set oral UPA (5 or $10 \mathrm{mg} /$ day) against placebo, ${ }^{22}$ while
PEARL II (PGL4001 versus GnRHa in uterine myomas) has compared UPA (5-10 mg/day) with the GnRHa leuprolide acetate (LA; one-monthly intramuscular injection, $3.75 \mathrm{mg}$ ). ${ }^{23}$ In both trials, treatment was started on one of the first 4 days of menstruation and was continued for 13 weeks.

In the PEARL I trial, patients were randomized to receive UPA 5 mg/day (96 women), or UPA 10 mg/day (98 women), or placebo (48 women). All patients received $80 \mathrm{mg}$ iron supplementation once daily during the active-treatment phase. Inclusion criteria were: premenopausal women between 18 and 50 years old with myomatous uterus, menorrhagia, and anemia. The uterus had to be equivalent in size to a pregnant uterus of $\leq 16$ weeks gestation, with at least one fibroid of $3 \mathrm{~cm}$ or more in diameter, but with no fibroid exceeding $10 \mathrm{~cm}$ diameter under magnetic resonance imaging. Fibroid-associated uterine bleeding was measured by the Pictorial Bleeding Assessment Chart (PBAC score) ${ }^{24}$ and values $>100$ on days $1-8$ of menstruation were considered eligible for inclusion. The presence of fibroid related anemia (hemoglobin level $\leq 10.2 \mathrm{~g} / \mathrm{dL}$ without macrocytosis) was another inclusion criterion. The primary endpoints were the efficacy of UPA versus placebo in controlling excessive bleeding (PBAC <75) and the reduction of fibroid volume at week 13. Secondary endpoints included amenorrhea, time

Table I Main clinical outcomes of PEARL I and PEARL II studies ${ }^{22,23}$

\begin{tabular}{|c|c|c|c|c|}
\hline Endpoint & Placebo & UPA 5 mg & UPA $10 \mathrm{mg}$ & Conclusion \\
\hline \multicolumn{5}{|l|}{ PEARL I } \\
\hline $\begin{array}{l}\text { Control of uterine bleeding (PBAC score } \\
<75 \text { at week 13) }\end{array}$ & $19 \%$ & $91 \%$ & $92 \%$ & Superiority of UPA versus placebo \\
\hline $\begin{array}{l}\text { Correction of anemia (hemoglobin }>12 \mathrm{mg} / \mathrm{dL} \\
\text { at week I3) }\end{array}$ & $77.1 \%$ & $85.3 \%$ & $89.4 \%$ & Superiority of UPA versus placebo \\
\hline $\begin{array}{l}\text { Shrinkage of fibroids (median \% of volume } \\
\text { reduction from basal at week 13) }\end{array}$ & $+3 \%$ & $-21.2 \%$ & $-12.3 \%$ & Superiority of UPA versus placebo \\
\hline Pain reduction & -2.5 & -5.0 & -5.6 & Superiority of UPA versus placebo \\
\hline $\begin{array}{l}\text { Adverse events leading to discontinuation } \\
\text { of study drug }\end{array}$ & $2 \%$ & $1 \%$ & $1 \%$ & \\
\hline Endpoint & LA $3.75 \mathrm{mg}$ & UPA 5 mg & UPA $10 \mathrm{mg}$ & Conclusion \\
\hline \multicolumn{5}{|l|}{ PEARL II } \\
\hline $\begin{array}{l}\text { Control of uterine bleeding } \\
\text { (PBAC score }<75 \text { at week I3) }\end{array}$ & $89 \%$ & $90 \%$ & $98 \%$ & Non inferiority of UPA versus LA \\
\hline $\begin{array}{l}\text { Shrinkage of fibroids (median \% of volume } \\
\text { reduction from baseline at week 13) }\end{array}$ & $-53 \%$ & $-36 \%$ & $-42 \%$ & $\begin{array}{l}\text { Not significant differences } \\
\text { between UPA and LA }\end{array}$ \\
\hline Pain reduction & -5.5 & -5.0 & -6.0 & $\begin{array}{l}\text { Not significant differences } \\
\text { between UPA and LA }\end{array}$ \\
\hline $\begin{array}{l}\text { Adverse events leading to discontinuation } \\
\text { of study drug }\end{array}$ & $6 \%$ & $1 \%$ & $2 \%$ & \\
\hline $\begin{array}{l}\text { Hot flushes (moderate to severe hot } \\
\text { flushes at week I3) }\end{array}$ & $40 \%$ & $11 \%$ & $10 \%$ & $\begin{array}{l}\text { Superiority of the tolerability } \\
\text { profile of UPA versus LA }\end{array}$ \\
\hline Estradiol levels at week I3 & $25 \mathrm{pg} / \mathrm{mL}$ & 64 pg/mL & $60.5 \mathrm{pg} / \mathrm{mL}$ & $\begin{array}{l}\text { Superiority of the tolerability } \\
\text { profile of UPA versus LA }\end{array}$ \\
\hline
\end{tabular}

Abbreviations: UPA, ulipristal acetate; PBAC, pictorial bleeding assessment chart; LA, leuprolide acetate. 
required to control bleeding, reduction in uterine volume, changes in hemoglobin values, pain, and quality of life. The latter were tested with a questionnaire assessing discomfort associated with uterine fibroids. Finally, the work assessed the overall tolerability of UPA considering treatment related adverse events and endometrial changes. ${ }^{22}$

The PEARL II trial analyzed the efficacy and tolerability of UPA in 307 patients with symptomatic fibroids, by comparing it with a GnRHa, LA. Patients were randomized to UPA 5 or $10 \mathrm{mg}$ once daily (97 and 103 women, respectively) or to a once-monthly intramuscular injection of LA $3.75 \mathrm{mg}$ (101 women). Inclusion criteria were similar to those of the previous study, except for anemia, that was not required. The study meant to demonstrate that UPA is not inferior to LA in reducing the uterine bleeding, as a primary endpoint. Moreover, the trial was aimed at proving the better tolerability profile of UPA in terms of estradiol levels and incidence of hot flushes. Secondary endpoints included bleeding pattern (consecutive 28-day PBAC scores), amenorrhea, changes from baseline in fibroid and uterine volume, pain, and quality of life tested with a questionnaire assessing discomfort associated with uterine fibroids. ${ }^{23}$

In the PEARL I trial, uterine bleeding was controlled at week 13 in $91 \%, 92 \%$, and 19\% women receiving UPA (5 mg), UPA (10 mg), and placebo, respectively. Thus, the PEARL I trial demonstrated the effectiveness of UPA in controlling uterine bleeding. ${ }^{22}$ Furthermore, the PEARL II trial proved that UPA is not inferior to GnRHa. In fact, uterine bleeding was controlled at week 13 in $90 \%, 98 \%$, and $89 \%$ of women receiving UPA $(5 \mathrm{mg})$, UPA $(10 \mathrm{mg})$, and LA, respectively. ${ }^{23}$

An important clinical feature is the time needed to control bleeding. In PEARL I bleeding control was achieved on day 8 in $>75 \%$ patients receiving 5 or $10 \mathrm{mg}$ UPA versus $6 \%$ being administered placebo. Amenorrhea occurred within the first 10 days of treatment in approximately half of the women treated with $5 \mathrm{mg}$ UPA and $70 \%$ treated with $10 \mathrm{mg}$ UPA. ${ }^{22}$ In PEARL II, 85\% women receiving $5 \mathrm{mg}$ of UPA and $60 \%$ receiving LA achieved bleeding control on day 10 . Thus, UPA allowed a quicker control of uterine bleeding when compared to LA. The median time required to achieve amenorrhea in the two groups was 7 and 21 days, while recurrence of menstruation after treatment withdrawal required 30-34 days in the UPA group and 43 days in the LA group, respectively. ${ }^{23}$

Such a quick effect has major advantages in anemic patients. In fact, in PEARL I, UPA administration was associated with higher hemoglobin and hematocrit levels than placebo, even though all patients received the same iron supplementation. In the 13th week, hemoglobin levels were $>12 \mathrm{~g} / \mathrm{dL}$ in $89.4 \%, 85.3 \%$, and $77.1 \%$ women receiving $5 \mathrm{mg}$ UPA, $10 \mathrm{mg}$ UPA, and placebo, respectively.

The shrinkage of fibroids was the primary endpoint in PEARL I and one of the secondary endpoints in PEARL II. The former proved that $5 \mathrm{mg}$ or $10 \mathrm{mg}$ UPA allowed a greater reduction in fibroid size, as measured at week 13, than placebo $\left(-21 \%,-12 \%\right.$, and $+3 \%$ respectively). ${ }^{22}$ In PEARL II, the reduction in the volume of the three largest uterine fibroids was comparable between the groups; however, the effect of UPA lasted longer. Women who did not undergo fibroid surgery were examined after 38 weeks of follow-up: the decrease in total fibroid volume was retained in UPA recipients, whereas it went back to the baseline in a high proportion of patients receiving LA. ${ }^{23}$

In the PEARL I trial, the administration of UPA $10 \mathrm{mg}$ was more efficient for pain reduction than placebo $(-5.6$ versus -2.5), while PEARL II failed to uncover any significant difference between the three groups at the end of treatment $(-5.0,-6.0$, and -5.5 , respectively). Both trials demonstrated an overall improvement in the quality of life of symptomatic women treated with UPA.

As we can infer from the results of both trials, the effect of a daily administration of $5 \mathrm{mg}$ UPA does not differ significantly from daily administration of $10 \mathrm{mg}$ UPA. Thus, the proposed dosage was set at $5 \mathrm{mg} /$ day, which was defined as the minimum effective dose of the drug. ${ }^{22,23}$

\section{Tolerability profile}

Both PEARL trials have assessed UPA tolerability. The most frequent adverse events were amenorrhea (even though it represents a target to reach rather than an adverse effect in the case of uterine fibroids), headache, flushes, dizziness, discomfort, and tenderness in the breast. In all, 94\% of patients reported adverse effects, describing their intensity as moderate, moreover such events resolved spontaneously at the end of treatment. As demonstrated by PEARL I, the choice of the drug did not influence the occurrence rate of any adverse events reported. ${ }^{22}$ Furthermore, the incidence of adverse events leading to drug discontinuation was $1 \%$, $1 \%$, and $2 \%$ in the groups treated with UPA $5 \mathrm{mg}$, UPA $10 \mathrm{mg}$, and placebo, respectively. Similar rates were reported in PEARL II: $1 \%, 2 \%$, and $6 \%$ patients treated with UPA $5 \mathrm{mg}$, UPA $10 \mathrm{mg}$, and LA, respectively, discontinued drug administration. ${ }^{23}$

PEARL II assessed estradiol levels and incidence of hot flushes as the primary endpoint. The incidence of hot flushes was recorded at week 13: UPA allowed a significant reduction in the incidence of moderate to severe hot flushes 
(11\% versus $40 \%) .{ }^{23}$ In women receiving UPA, plasma estradiol levels were steadily within the midfollicular range (60-150 pg/mL), as confirmed by both trials. On the contrary, LA was associated to significantly lower estradiol levels ( $25 \mathrm{pg} / \mathrm{mL}$ versus $64 \mathrm{pg} / \mathrm{mL}$ ), resulting in the occurrence of menopausal symptoms and bone loss. ${ }^{22,23}$

\section{Effects of ulipristal acetate on the endometrium}

PRMs have been recently introduced in the clinical management of premenopausal women due to their powerful progesterone antagonist action. However, this could result in unopposed estrogen stimulation, increasing the risk of hyperplasia and endometrioid carcinoma. These observations inspired a workshop held in Bethesda in April 2006. The workshop, entitled Progesterone Receptor Modulators and the Endometrium, dealt with the long-term safety of treatment and the endometrial changes induced by PRM. After examining the biopsies from women included in four clinical trials with different PRMs (mifepristone, CDB2914, JNJ 17072341, and asoprisnil), a group of experts defined a common terminology and introduced specific recommendations for pathologists. ${ }^{25}$ Various endometrial findings were described, but they did not include malignant and premalignant changes. Some endometrial patterns resembled those observed during a normal endometrial cycle or other benign conditions, but some were unclassifiable on the basis of the available criteria and were designated PRM-associated endometrial changes (PAECs).

Some of the endometrial aspects reported in PAECs are induced by hormonal depletion as well as estrogen or progesterone stimulation. Most of the glands appear tubular, with rare coiling, and are surrounded by compact stroma that does not display any evidence of stromal breakdown. Glands are lined by low columnar to cuboidal epithelium showing varying degrees of secretory activity and ciliated metaplasia; scattered mitoses and apoptosis have been noticed even in individual glands. Cystic glands are common and may be numerous and confluent with flaccid walls. The stroma varies from fibrous to composed of plumped cells, without any evidence of predecidual change. Moreover, it shows a specific vascular pattern characterized by a network of capillaries in a chicken wire pattern and dispersed thick walled vessels. Occasional dilated vessels with prominent endothelium may be seen, but no evidence of fibrin thrombi has been reported. ${ }^{25}$

The endometrial biopsies taken in PEARL I and PEARL II allowed a detailed description of the endometrial effects of UPA (Table 2). The histologic features induced by UPA were compared to those detected in two control groups (women treated with placebo and patients receiving LA, respectively) at three different time points: at screening, at 3 months of

Table 2 Adequacy of biopsies, observed lesions, non-physiological tissue, extensive cyst formation, and endometrium thickness $>16 \mathrm{~mm}$ at screening and after I 3 and 38 weeks (data from two Phase III studies, PEARL I and II) $22,23,26$

\begin{tabular}{|c|c|c|c|c|c|c|}
\hline & \multicolumn{3}{|l|}{ PEARL I } & \multicolumn{3}{|l|}{ PEARL II } \\
\hline & $\begin{array}{l}\text { Placebo } \\
(n=48)\end{array}$ & $\begin{array}{l}\text { UPA } 5 \mathrm{mg} \\
(\mathrm{n}=95)\end{array}$ & $\begin{array}{l}\text { UPA } 10 \mathrm{mg} \\
(\mathrm{n}=98)\end{array}$ & $\begin{array}{l}\text { UPA } 5 \mathrm{mg} \\
(n=97)\end{array}$ & $\begin{array}{l}\text { UPA } 10 \mathrm{mg} \\
(\mathrm{n}=103)\end{array}$ & $\begin{array}{l}\text { GnRHa } \\
(n=\mid 0 I)\end{array}$ \\
\hline \multicolumn{7}{|l|}{ Adequacy of biopsies (\%) } \\
\hline Screening & 100 & 92.6 & 96.9 & 91.8 & 97.1 & 90.1 \\
\hline Week I3 (end of treatment) & 95.1 & 94.0 & 96.3 & 91.5 & 96.9 & 92.6 \\
\hline Week 38 & 96.8 & 95.2 & 96.8 & 92.1 & 92.5 & 93.7 \\
\hline \multicolumn{7}{|l|}{ Observed lesions (n) } \\
\hline Screening & - & $\mathrm{I} \mathrm{H}$ & - & $\mathrm{I} \mathrm{H}, 2 \mathrm{P}$ & - & I P \\
\hline Week I 3 (end of treatment) & - & $\mathrm{IP}$ & I P & I H, I P & I P & $\mathrm{IP}$ \\
\hline Week 38 & $\mathrm{I} \mathrm{H}$ & I P & - & - & - & $\mathrm{I} \mathrm{H}$ \\
\hline \multicolumn{7}{|l|}{ Nonphysiological tissue (\%) } \\
\hline Screening & 8.4 & 10.0 & 8.5 & 6.1 & 6.4 & 4.4 \\
\hline Week I3 (end of treatment) & 14.4 & 74.2 & 70.4 & 65.1 & 64.7 & 17.7 \\
\hline Week 38 & 7.1 & 14.2 & 12.9 & 17.3 & 9.9 & 11.2 \\
\hline \multicolumn{7}{|l|}{ Extensive cyst formation (\%) } \\
\hline Screening & 0 & 0.4 & 0 & 0 & 0.7 & 0.7 \\
\hline Week I 3 (end of treatment) & 0.9 & 45.1 & $4 I . I$ & 37.6 & 38.2 & 3.6 \\
\hline Week 38 & 0 & 5.1 & 3.9 & 4.2 & 0.5 & 3.9 \\
\hline \multicolumn{7}{|c|}{ Endometrium thickness $>16 \mathrm{~mm}(\%)$} \\
\hline Screening & 0 & I.I & 2.3 & 5.2 & 5.0 & 4.0 \\
\hline Week I3 (end of treatment) & 2.1 & 11.2 & 8.0 & II.8 & 15.3 & I.I \\
\hline Week 38 & 4.2 & 4.8 & 2.6 & 6.0 & 2.9 & 4.4 \\
\hline
\end{tabular}

Abbreviations: GnRHa, leuprolide; H, hyperplasia; P, polyp; UPA, ulipristal acetate. 
treatment and at 38 weeks, after treatment discontinuation. Polyps occurred in four UPA-treated women versus two patients receiving placebo and two being administered GnRHa; hyperplasia without atypia was detected only in one patient receiving $5 \mathrm{mg}$ of UPA, after 3 months of treatment. ${ }^{26}$ PAECs were found in 59.7\% and 54.5\% women treated with $5 \mathrm{mg}$ of UPA. Furthermore, PAECs were reported in $56.4 \%$ and $61.3 \%$ women treated with $10 \mathrm{mg}$ in PEARL I and II, respectively. Such characteristics regressed in week 13, after discontinuation of treatment, and their incidence was comparable to the one reported in the placebo and in the GnRHa group. Extensive cyst formation was observed in one third of the women treated with UPA and in $<1 \%$ of women belonging to the placebo group. Among PRM-specific endometrial changes, extensive cyst formation is quite peculiar, but it may be confused with disordered proliferative endometrium or simple, non-atypical endometrial hyperplasia arising from unopposed estrogen effect. However, the endometrial features of the afore mentioned pathologic conditions differ from PAEC in UPA-treated patients, and include:

1. low mitotic activity in both glands and stroma;

2. abortive sub-nuclear vacuoles;

3. apoptosis;

4. absence of stromal breakdown and glandular crowding.

The typical changes induced by unopposed estrogen are not detected with SPRM. The explanation of this paradoxical mechanism is still obscure. In addition to that, a slight increase in the mean endometrial thickness of treated patients has been observed radiologically. In PEARL I and PEARL II studies, endometrial thickness exceeding $16 \mathrm{~mm}$ was reported in $3 \%-5 \%$ cases at baseline and in up to $10 \%-15 \%$ cases after 3 months of UPA administration. This phenomenon spontaneously regressed after discontinuation of treatment (week 17). ${ }^{26-30}$

\section{Discussion}

Nowadays, no currently validated medical treatment causes fibroid elimination and hence surgery still represents the most effective treatment for symptomatic fibroids. The surgical approach and the type of surgery depends on several factors, including the severity of the symptoms, the volume of the fibroids, the size of the uterus, and the patient's age. In several cases, hysterectomy is the treatment of choice, even though it causes infertility in reproductive age women. ${ }^{31}$

Selected cases of patients with small uterine fibroids who wish to preserve fertility can be administered a pharmacological symptomatic therapy. To date, GnRH analogues were the only drugs available for the preoperative treatment of fibroids. Their use could be limited by several factors:

1. the control of bleeding is clinically relevant only after three months of therapy;

2. GnRHa are administered by injection, thereby limiting patient compliance;

3. the deep suppression of estrogen levels induces postmenopausal symptoms (hot flushes, mood swings, bone density loss);

4. after drug withdrawal fibroids slowly go back to pretreatment size. ${ }^{13,32-34}$

UPA may be a new, effective, and well-tolerated option for the preoperative control of moderate and severe symptoms in reproductive age women with uterine fibroids. So far, the available studies dealing with 3 -months-long UPA administration yielded the following results: ${ }^{22,23}$

- UPA rapidly controls uterine bleeding, acting faster than LA, while keeping the same effectiveness;

- the significant reduction in fibroid size allowed by UPA is maintained for at least 6 months after treatment withdrawal. This time interval is longer than reported for leuprolide;

- UPA significantly improves hemoglobin and hematocrit levels in anemic patients, and it is associated with better pain control and higher quality of life;

- when compared to LA, UPA shows a better tolerability profile: in fact, estradiol levels are kept within the normal range, and studies report fewer hot flushes and no impact on bone turnover.

The preoperative treatment with UPA might be useful for several clinical conditions. Firstly, it could be administered to patients waiting for surgery in order to achieve clinical control of the symptoms (in particular it could prevent the worsening of anemia) and possibly making surgery less invasive. Additionally, one should also consider that the reduction in uterine fibroid size lasts longer when UPA is administered. This property appears advantageous when surgery is postponed after 3 months of pre-treatment. Furthermore, beneficial effects are not limited to the long-term. In fact, UPA has been proven to rapidly control bleeding and to restore hemoglobin and hematocrit levels quickly. These benefits could be exploited when surgery must be performed before the time scheduled and in the case of anemic patients in general. Finally, UPA may be a good option for women seeking pregnancy, for several reasons; in fertile women, UPA can grant an asymptomatic window in which sexual intercourse should be targeted to allow spontaneous conception. Moreover, UPA effectively reduces the invasiveness of 
surgery, thereby preserving a woman's fertility and improving obstetric outcomes (reduced risk of uterine rupture and need of cesarean section). Infertile patients, and also in vitro fertilization (IVF) candidates, would benefit from UPA administration, as it allows for postponing surgery after childbearing.

Another interesting category includes pre-menopausal women, in whom UPA could control the symptoms until the onset of spontaneous menopause and avoid hysterectomy. Besides, when a prolonged treatment is required, the postmenopausal symptoms are more frequent with LA than with UPA. ${ }^{11}$

Besides being advantageous in specific patient categories, UPA allows optimization of surgical interventions and facilitates the scheduling of surgery rooms. In fact, UPA pre-surgical treatment could reduce emergency surgery, allow a better outpatient management, and streamline the waiting list for surgery.

A finding of potential clinical interest is the occurrence of endometrial changes (PAECs) in patients receiving UPA. Endometrium treated with short term UPA shows reversible changes, which are included in the range of histologic alterations induced by SPRMs in general. These endometrial changes are known as PAEC, and the major ones are the development of cystic changes and the increase in endometrial thickness.

Since the endometrial thickness is restored to baseline levels after treatment discontinuation, PAECs are considered a reversible pharmacodynamic response to the administration of UPA in most situations. In order to avoid unnecessary investigations and treatment, these specific changes should not be confused with disordered proliferative endometrium, unopposed estrogen effect, or endometrial hyperplasia.

UPA differs from the other available medical treatments for uterine fibroids (LA) in terms of both mechanism of action and route of administration (oral versus injectable), but it is equally effective for treating bleeding and myoma size reduction. ${ }^{34}$ Moreover, it has faster acting and more prolonged effects, along with a better tolerability and safety profile. However, further studies are needed to investigate some issues that are presently unclear, including: the entire mechanism of action, the effect of UPA on the endometrial vascularization, its influence on the choice of the type of surgery, as well as the possibility to avoid it completely, and finally the drug safety when pregnancy occurs after treatment. On the other hand, studies assessing the efficacy of UPA as a long-term treatment for uterine fibroids are ongoing.

In conclusion, UPA $5 \mathrm{mg} /$ day for 3 months may be a good option for patients with symptomatic uterine fibroids in order to plan a treatment strategy tailored to meet patients' individual needs.

\section{Disclosure}

The authors report no conflicts of interest in this work.

\section{References}

1. Okolo S. Incidence, aetiology and epidemiology of uterine fibroids. Best Pract Res Clin Obstet Gynaecol. 2008;22(4):571-588.

2. Marshall LM, Spiegelman D, Barbieri RL, et al. Variation in the incidence of uterine leiomyoma among premenopausal women by age and race. Obstet Gynecol. 1997;90(6):967-973.

3. Rein MS, Barbieri RL, Friedman AJ. Progesterone: a critical role in the pathogenesis of uterine myomas. Am J Obstet Gynecol. 1995;172(1 Pt 1): $14-18$.

4. Andersen J. Growth factors and cytokines in uterine leiomyomas. Semin Reprod Endocrinol. 1996;14:269-282.

5. Fields KR, Neinstein LS. Uterine myomas in adolescents: case reports and a review of the literature. J Pediatr Adolesc Gynecol. 1996;9(4):195-198.

6. Zimmermann A, Bernuit D, Gerlinger C, Schaefers M, Geppert K. Prevalence, symptoms and management of uterine fibroids: an international internet-based survey of 21,746 women. BMC Womens Health. 2012;12:6

7. Ke LQ, Yang K, Li J, Li CM. Danazol for uterine fibroids [review]. Cochrane Database Syst Rev. 2009;3:CD007692.

8. Murat Naki M, Tekcan C, Ozcan N, Cebi M. Levonorgestrel-releasing intrauterine device insertion ameliorates leiomyoma-dependent menorrhagia among women of reproductive age without a significant regression in the uterine and leiomyoma volumes. Fertil Steril. 2010;94(1):371-374.

9. Zapata LB, Whiteman MK, Tepper NK, Jamieson DJ, Marchbanks PA, Curtis KM. Intrauterine device use among women with uterine fibroids: a systematic review. Contraception. 2010;82(1):41-55.

10. Ikomi A, Pepra EF. Efficacy of the levonorgestrel intrauterine system in treating menorrhagia: actualities and ambiguities. J Fam Plann Reprod Health Care. 2002;28(2):99-100.

11. Lethaby AE, Vollenhoven BJ. An evidence-based approach to hormonal therapies for premenopausal women with fibroids. Best Pract Res Clin Obstet Gynaecol. 2008;22(2):307-331.

12. Stovall TG, Muneyyirci-Delale O, Summitt RL, Scialli AR. GnRH agonist and iron versus placebo and iron in the anemic patient before surgery for leiomyomas: a randomized controlled trial. Leuprolide Acetate Study Group. Obstet Gynecol. 1995;86(1):65-71.

13. Lethaby A, Vollenhoven B, Sowter MC. Preoperative GnRH analogue therapy before hysterectomy or myomectomy for uterine fibroids [review]. Cochrane Database Syst Rev. 2001;2:CD000547.

14. Varelas FK, Papanicolaou AN, Vavatsi-Christaki N, Makedos GA, Vlassis GD. The effect of anastrazole on symptomatic uterine leiomyomata. Obstet Gynecol. 2007;110(3):643-649.

15. Parsanezhad ME, Azmoon M, Alborzi S, et al. A randomized, controlled clinical trial comparing the effects of aromatase inhibitor (letrozole) and gonadotropin-releasing hormone agonist (triptorelin) on uterine leiomyoma volume and hormonal status. Fertil Steril. 2010;93(1):192-198.

16. Tamaya T, Fujimoto J, Okada H. Comparison of cellular levels of steroid receptors in uterine leiomyoma and myometrium. Acta Obstet Gynecol Scand. 1985;64(4):307-309.

17. Maruo T, Matsuo H, Samoto T, et al. Effects of progesterone on uterine leiomyoma growth and apoptosis. Steroids. 2000;65(10-11): 585-592.

18. Chwalisz K, Perez MC, Demanno D, Winkel C, Schubert G, Elger W. Selective progesterone receptor modulator development and use in the treatment of leiomyomata and endometriosis. Endocr Rev. 2005;26(3): 423-438. 
19. Chabbert-Buffet N, Meduri G, Bouchard P, Spitz IM. Selective progesterone receptor modulators and progesterone antagonists: mechanisms of action and clinical applications. Hum Reprod Update. 2005;11(3):293-307.

20. Spitz IM. Clinical utility of progesterone receptor modulators and their effect on the endometrium. Curr Opin Obstet Gynecol. 2009;21(4): 318-324.

21. Talaulikar VS, Manyonda I. Progesterone and progesterone receptor modulators in the management of symptomatic uterine fibroids. Eur $J$ Obstet Gynecol Reprod Biol. 2012;165(2):135-140.

22. Donnez J, Tatarchuk TF, Bouchard P, et al; PEARL I Study Group. Ulipristal acetate versus placebo for fibroid treatment before surgery. N Engl J Med. 2012;366(5):409-420.

23. Donnez J, Tomaszewski J, Vázquez F, et al; PEARL II Study Group Ulipristal acetate versus leuprolide acetate for uterine fibroids. $N \mathrm{Engl}$ J Med. 2012;366(5):421-432.

24. Higham JM, O'Brien PM, Shaw RW. Assessment of menstrual blood loss using a pictorial chart. Br J Obstet Gynaecol. 1990;97(8): 734-739.

25. Mutter GL, Bergeron C, Deligdisch L, et al. The spectrum of endometrial pathology induced by progesterone receptor modulators. Mod Pathol. 2008;21(5):591-598.

26. Williams AR, Bergeron C, Barlow DH, Ferenczy A. Endometrial morphology after treatment of uterine fibroids with the selective progesterone receptor modulator, ulipristal acetate. Int J Gynecol Pathol. 2012;31(6):556-569.
27. Bläuer M, Heinonen PK, Rovio P, Ylikomi T. Effects of tamoxifen and raloxifene on normal human endometrial cells in an organotypic in vitro model. Eur J Pharmacol. 2008;592(1-3):13-18.

28. Noyes RW, Hertig AT, Rock J. Dating the endometrial biopsy. Am J Obstet Gynecol. 1975;122(2):262-263.

29. Hendrickson MR, Longacre TA, Keempson RL. The uterine corpus. In: Sternberg SS, editor. Diagnostic Surgical Pathology. Philadelphia: Lippincott; 1999:2203-2204.

30. Biron-Shental T, Tepper R, Fishman A, Shapira J, Cohen I. Recurrent endometrial polyps in postmenopausal breast cancer patients on tamoxifen. Gynecol Oncol. 2003;90(2):382-386.

31. Frederick J, Hardie M, Reid M, Fletcher H, Wynter S, Frederick C. Operative morbidity and reproductive outcome in secondary myomectomy: a prospective cohort study. Hum Reprod. 2002;17(11):2967-2971.

32. Friedman AJ, Lobel SM, Rein MS, Barbieri RL. Efficacy and safety considerations in women with uterine leiomyomas treated with gonadotropin-releasing hormone agonists: the estrogen threshold hypothesis. Am J Obstet Gynecol. 1990;163(4 Pt 1):1114-1119.

33. Brosens IA. Variable response of uterine leiomyomas after GnRH agonist therapy. Fertil Steril. 1997;68(5):948-949.

34. Maheux R, Guilloteau C, Lemay A, Bastide A, Fazekas AT. Regression of leiomyomata uteri following hypoestrogenism induced by repetitive luteinizing hormone-releasing hormone agonist treatment: preliminary report. Fertil Steril. 1984;42(4):644-646.
Drug Design, Development and Therapy

\section{Publish your work in this journal}

Drug Design, Development and Therapy is an international, peerreviewed open-access journal that spans the spectrum of drug design and development through to clinical applications. Clinical outcomes, patient safety, and programs for the development and effective, safe, and sustained use of medicines are a feature of the journal, which

\section{Dovepress}

has also been accepted for indexing on PubMed Central. The manuscript management system is completely online and includes a very quick and fair peer-review system, which is all easy to use. Visit http://www.dovepress.com/testimonials.php to read real quotes from published authors.

Submit your manuscript here: http://www.dovepress.com/drug-design-development-and-therapy-journal 